\title{
High temperature systems using solid particles as TES and HTF material: a review
}

\author{
Alejandro Calderón ${ }^{1}$, Anabel Palacios ${ }^{1}$, Camila Barreneche $^{1}$, Mercè Segarra ${ }^{1}$, Cristina Prieto $^{2}$, \\ Alfonso Rodriguez-Sanchez ${ }^{2}$, A. Inés Fernández ${ }^{1, *}$ \\ ${ }^{1}$ Department of Materials Science and Physical Chemistry, Universitat de Barcelona, Martí i Franquès 1- \\ 11, Barcelona 08028, Spain. Tel.: +934021317. ana_inesfernandez@ub.edu \\ ${ }^{2}$ Abengoa Solar New Technologies S.A., C/Energía Solar 1, 41014, Sevilla
}

\begin{abstract}
Thermal energy constitutes up to $90 \%$ of global energy budget, centering on heat conversion, transmission, and storage; therefore, the technology for harvesting solar energy worth to be developed. One of them is the concentrated solar power (CSP) solar towers where suntracking heliostats reflect solar radiation to the top of a tower where the receiver is located. The great advantage of CSP over other renewable energy sources is that energy storage is feasible, particularly when the heat transfer fluid (HTF) is also used as thermal energy storage (TES) material which is the case of solid particles. A lot of development efforts are under way for achieving commercial direct solar solid-particle systems. Solid particle systems for transferring high temperature thermal energy are purposed for increasing the efficiency of these systems when converting heat into electric power. This review recapitulates the concept of these systems taking into account the main receiver designs, particle conveyance, particle storage systems and components, the heat exchanger, and the main challenges that must be overcome to split this technology as a commercial one, especially from the materials availability point of view. This review summarizes the actual status of the use of solid particles for TES and as HTF for CSP Tower, and condenses all the available information and classifies them considering the main functional parts and remarking the current research in each part as well as the future challenging issues.
\end{abstract}

Keywords: Concentrated solar power, solid particles, thermal energy storage, sensible heat storage, CSP components, solar power tower, heat exchanger, solid particle receiver. 


\section{Table of contents}

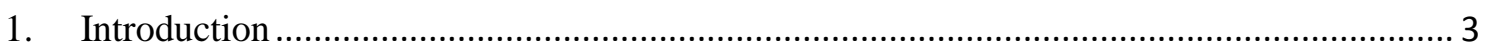

2. Solid Particle for use on Concentrating Solar Power (CSP) …......................................... 5

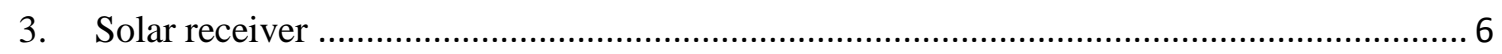

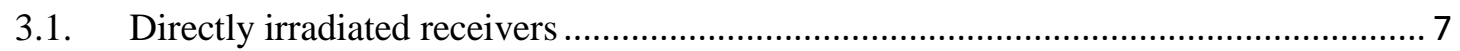

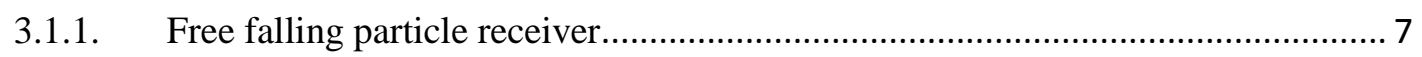

3.1.2. Obstructed particle flow receiver ............................................................... 9

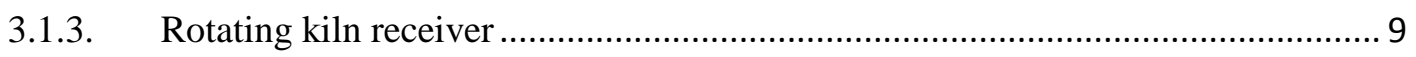

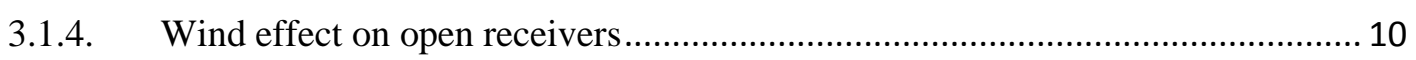

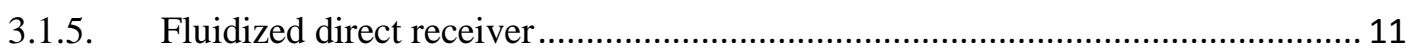

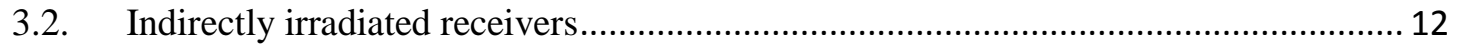

3.2.1. Particle flow integrated with heat exchanger (HEX) receiver............................. 12

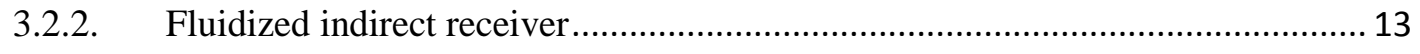

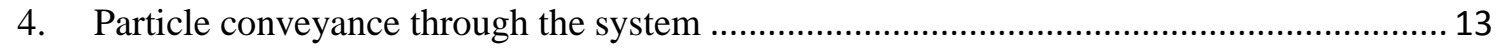

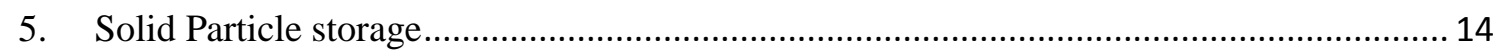

6. Heat exchanger between solid particles and the electricity generation cycle....................... 16

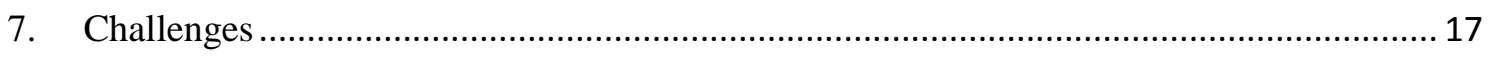

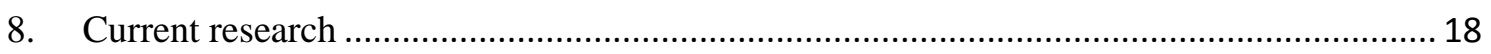

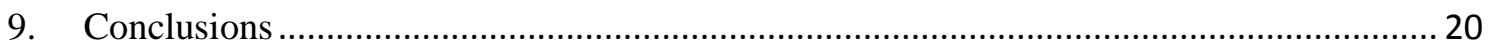

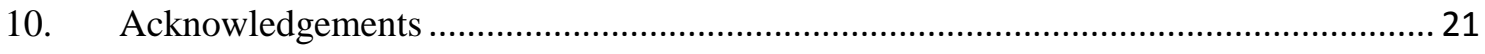

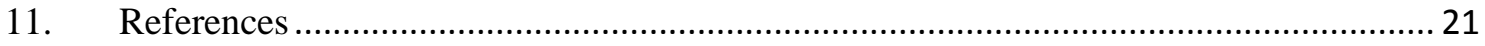




\section{Introduction}

Thermal energy constitutes up to $90 \%$ of global energy budget, centering around heat conversion, transmission, and storage [1]. Almost all this thermal energy comes directly or indirectly from sunlight. Therefore, the technology for harvesting solar energy is worth to be developed. Concentrating sunlight technologies allow increasing the operation temperature by increasing the type of applications and their efficiency.

Concentrating Solar Power (CSP) potential changes according to the region where is developed. Moreover, CSP can reach up to $11.3 \%$ of global electricity production with the appropriate support [2]. The installed capacity of CSP in 2015 reached 4,650 MW compared with 1,256 MW on 2010 [3]. Global technical potential of CSP amounts to almost 3,000,000 TWh/y against 22,000 TWh/y consumed globally on electricity [4,5]. It is expected that CSP will reach more installed capacity that geothermal [6]. CSP technologies have most favorable potential for North Africa, the Middle East, northwestern India, the southwestern United States, Mexico, Peru, Chile, the western part of China and Australia; and more moderate potential on extreme southern Europe, Turkey, central Asian countries, Brazil, Argentina and other locations on USD and China [2,7]. Initially CSP were more developed on Spain and the United States, but recently other markets are developing CSP plants such as de $160 \mathrm{MW}$ plant on Auarzazete, Morocco [6].

Solar energy can be harnessed by different technologies [8,9]. Particularly, CSP with central tower is a promising option because of the high power that can be reached, high efficiency of the power block (due to the high temperatures that can be reached), high land efficiency and large scale heat storage [2,4]. On CSP towers, sun-tracking heliostats reflect solar radiation to the top of a tower where the receiver, or solar absorber, is located [10]. Then, solar heat is transferred to a heat transfer fluid (HTF) in the receiver [11], in order to get the heat energy input into the system. After the receiver captures the heat on the HTF, thermal energy is transported either for conversion or for storage. The energy transport consists on moving the HTF through the system pipe network that connects the storage and energy exchange systems. If the energy conversion takes place on a different cycle, the collected thermal energy is carried away by the HTF that will transfer heat to the electricity conversion cycle (or power block) using a heat exchanger (HEX) [12]. Nevertheless, when the energy is stored for further use on conversion, there are two options to store it: the first is to keep the HTF in a storage device, and the second to use a HEX to store heat in a different media.

Unlike other renewable energy sources (except hydro), solar thermal CSP plants have the inherent capacity to store high inventory of energy (in form of heat) for later conversion to electricity [2] at low cost. In this case, it is desirable that the HTF and thermal energy storage (TES) material is the same.

CSP-TES systems are classified depending on whether it has an active or passive TES, a direct or indirect storage unit, or if the system is open or closed (only for active) [5]. Active TES is divided into direct storage, which refers when the HTF is used as the heat storage medium, and indirect storage, when other material is heated using a heat exchanger in order to save heat [13]. CSP-TES closed systems use controlled pressure and environment inside the system, while open systems use the same outside ambient atmospheric conditions for the control. Finally, these systems can also be classified depending on the kind of receiver used and if the HTF is directly or indirectly (using another material/structure as HEX) irradiated by the concentrated sunlight [14]. 
The main motivations for developing and enhancing CSP systems are: increasing the temperature (thus making thermal energy to electricity conversion more efficient), decreasing energy losses from receivers (and therefore using a smaller solar field), and using low cost materials that could meet the optimal operating conditions [12]. The current state of the art of the technology that has better commercial application for CSP towers is the one that uses molten salts as HTF [15], and has the advantage that it is also a good energy storage medium [12,16]. The major drawback of molten salt systems is the allowable operating temperature range, which is limited by the temperature of solidification of the solar salt at the low end, and the onset of thermal decomposition and corrosiveness at the high end [17]. Because of this, conventional central receiver technologies are limited to temperatures of around $565^{\circ} \mathrm{C}$ [15]. For higher temperatures, molten nitrate salt (the most common salt used) becomes chemically unstable, producing oxide ions that are highly corrosive, which results in significant mass loss [18], and corrosion thru the storage, HEX, receiver and conveyance system [16].

One solution to overcome these drawbacks is using solid particles as TES material and HTF [11]. The solid particle TES system achieves both high performance at high temperature, and low cost from the material perspective [19]. Direct absorption receivers using solid particles that fall through a beam of concentrated solar radiation for direct heat absorption and storage have the potential to increase the maximum temperature of the heat transfer media to more than 1000 ${ }^{\circ} \mathrm{C}$ [20]. A CSP system that operates from $600{ }^{\circ} \mathrm{C}$ to more than $1000{ }^{\circ} \mathrm{C}$ is possible because of the use of stable materials and the minimized thermal losses due to thermal self-insulation of particles in the storage medium [21]. The material and maintenance costs are expected to be lower for solid media storage systems [17].

Thus, solid particles have three main advantages as storage media, relative to more conventional materials such as molten salts:

- They are chemically inert and stable beyond $1100{ }^{\circ} \mathrm{C}$.

- They are capable of storing energy over a greater temperature span (effectively increasing storage density in a sensible energy-based system)

- They are expected to be relatively low cost.

The first studies on direct absorption solar receivers started in the early 1980s with two concepts, the fluidized bed receiver and the free falling particles receiver. In the first concept, the solid particles were fluidized in a transparent tube but did not flow outside, there was no solid circulation. In the free-falling particles curtain concept, the solid drop directly into the concentrated solar beam from the top of the receiver, and is heated during the time of its pass through the concentrated radiation. Particle selection and radiative heat transfer modeling have been proposed [22,23]. After about twenty years without significant new developments, this concept has been again proposed as a promising option for a new generation of high temperature solar thermal concentrating plants. Improved models have been developed and validated by on-sun experiments at pilot scale [11,24-28].

This review summarizes the actual status of the use of solid particles for TES and as HTF for CSP Tower applications taking into consideration the main components of the technology: the receiver, the heat exchanger and the TES unit. Moreover, the review condenses all the available information and classifies them considering the main functional parts and remarking the current research in that part as well as the future challenging issues. 


\section{Solid Particle for use on Concentrating Solar Power (CSP)}

Several development efforts are under way for achieving commercial direct solar solid-particle open systems. Several studies, simulations, experiments and pilot plant tests have been or are being performed including receiver design, conveyance systems, material storage and heat exchangers. Nevertheless, the solid-particle material itself has been studied according to the plant engineering specifications, and the availability of materials or a formal material selection has not been performed.

The main approach consists in concentrating solar power reflected by heliostats in a central tower, which has a receiver for capturing concentrated sunlight into the solid particles. This particles are moved across a specially designed conveyance system to a first storage, in which material is stored until its moved (by a fluidized bed system) into a heat exchanger (HEX) in order to transfer the heat to a generation cycle. After losing heat, the particle material is stored in a second silo before getting moved again to the receiver [19]. Solid Particle CSP general concept is shown in Figure 1.This system is similar to the current state-of-the-art molten salts system[29], but almost all the components must be specially designed for working with solid particles.

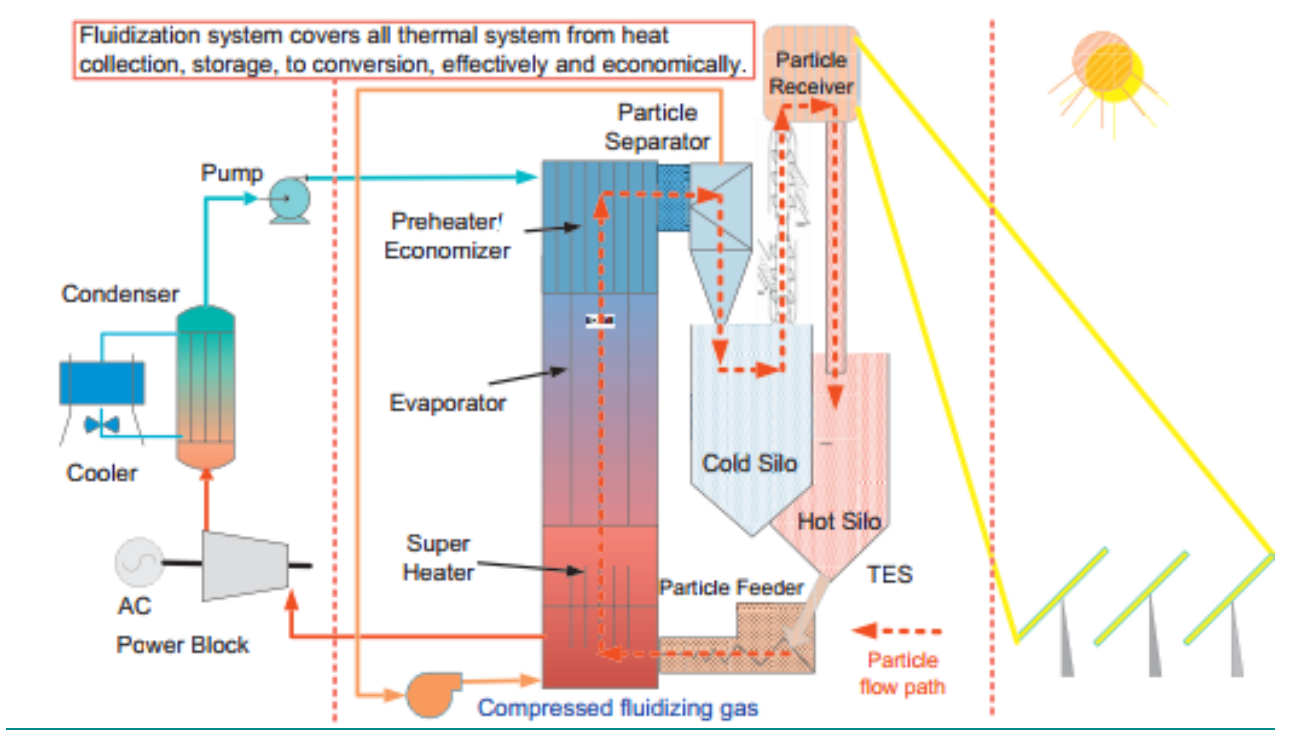

Figure 1. CSP solid particle system with TES and fluidized bed [21].

Current CSP central tower receiver systems are limited to power-cycle efficiencies up to $40 \%$. By reaching temperatures over $650{ }^{\circ} \mathrm{C}$, power-cycle efficiency can increase up to $50-60 \%$ by using more efficient thermodynamic cycles that require higher operation temperature (like Brayton cycle) [20,30-32]. Additional to this, cheaper thermal storage will be allowed, lowering the leveled cost of electricity [20]. 


\section{Solar receiver}

There are several studies suggesting different designs for particle receivers[14,18,21,26,33-41]. Nonetheless, there are some receivers more developed that can be categorized as shown in Figure 2. A receiver that is designed to allow the HTF to absorb directly the solar irradiance is called Direct Receiver; therefore, a receiver in which the HTF receives the heat from another material that has received the solar irradiance is called an Indirect Receiver.

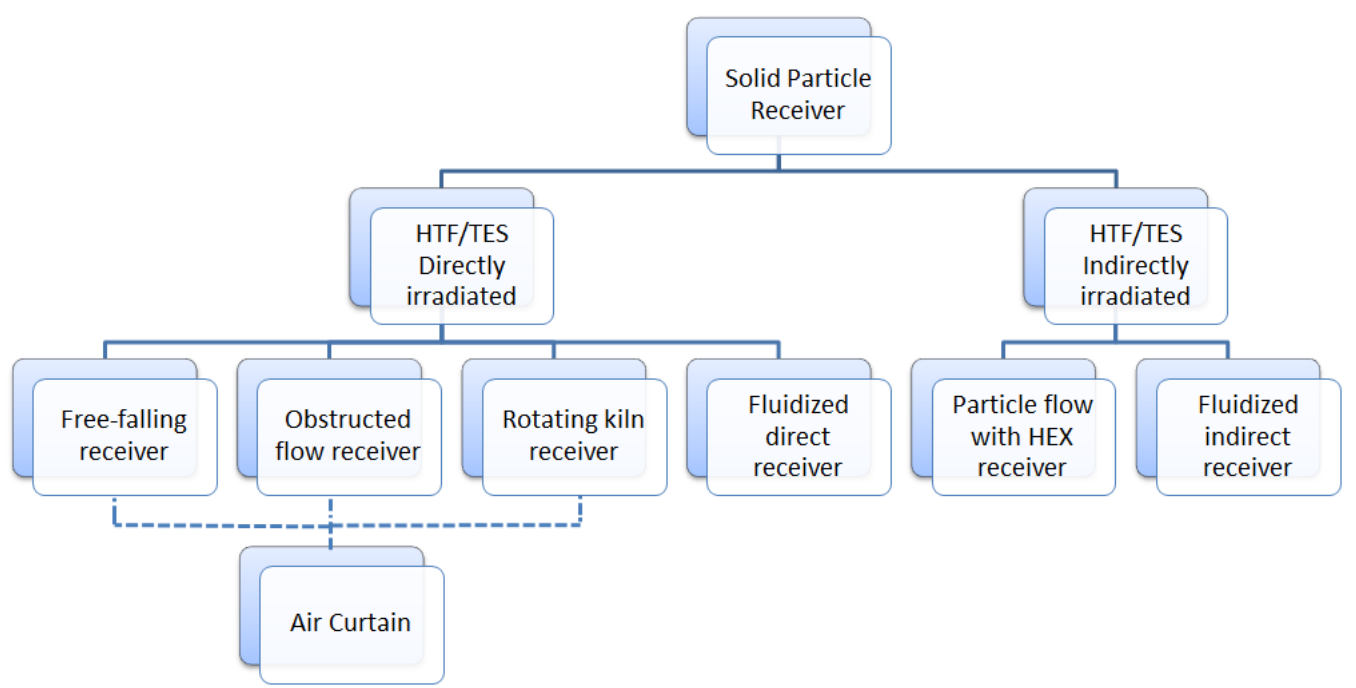

Figure 2. Solid particle receiver classification

The receivers are subcategorized according to their work principle. The most remarkable Direct Receivers are the Free-falling particle receiver, the Obstructed flow receiver, the Rotating kiln receiver and the Fluidized receiver. For the Indirect Receivers Particle flow with HEX receiver and the fluidized indirect receiver are the most developed.

Other related particle receiver designs and experimental evaluations have been performed, but they are not under the mentioned classification. Bertocchi [34] reported an experimental evaluation of a receiver which achieved temperatures over $2100 \mathrm{~K}$. It consisted in a conical cavity isolated from ambient conditions by a quartz window. On this design, a gas/particle suspension was conducted at the focal plane near the window [42]. Another approach proposes to incorporate gas-based Brayton cycles, with the objective of increasing overall efficiency, and eliminate cooling water requirements [32,39].

A way to evaluate the performance of a receiver is the absorptance efficiency (also called collection efficiency). It is calculated by obtaining the ratio of the heat captured by the particles to the solar energy received, and it has a dependent relation to the solar absorption captured by the receiver [43]. Nonetheless the material has an important role to determine the absorptivity efficiency; it allows measuring the efficiency due to the receiver principle of work and design.

Nevertheless different approaches have been proposed, there are no studies available about the material compatibility between the HTF-TES material and the material in used to build the receivers. Also, the designs don't consider any of the interactions with the HTF-TES material properties and stability. Some of these interactions have been observed until prototype plant development [27] but there has not been reported any proper material selection. 
Free falling receiver design was the first particle receiver conceived on the early 1980s by Sandia National Laboratories [44-46]. Despite the original interest on the 1980s [44-48], the research stopped until late 2000s, when solid particle receivers gain attention because of the molten salts central tower CSP efficiency-temperature limitations; and it has been under continuous development since then. Figure 3 illustrates this increasing development based on the publications related showed on 5 year periods. Also, a projection is showed based on the number of publications reached in 2016 and the beginning of 2017 (dotted line). The projection was performed accounting the amount of publications during these two years. Then, this value was divided per month and extrapolating the result was the calculation use to produce this projection.

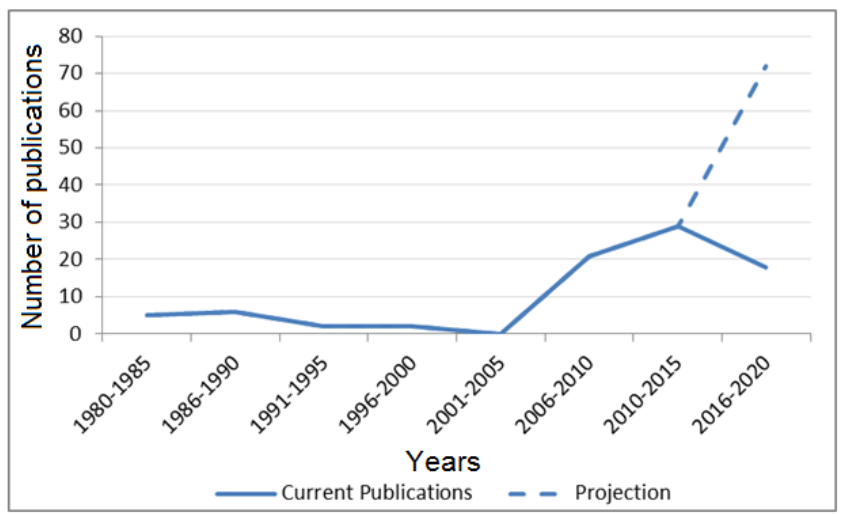

Figure 3. Bibliometric statistics on CSP free falling receivers.

\subsection{Directly irradiated receivers}

The most innovative designs have been proposed for direct receivers; this is mainly because it is required to increase the irradiation exposure time of the HTF material to achieve the high temperatures desired. For directly irradiated receiver the importance of solid particle material absorptance is a priority [43].

\subsubsection{Free falling particle receiver}

The first approach for this design was developed during the 1980s. The design considered that the material should fall through a the receiver forming a material curtain (Figure 4) but the temperature that the material could achieve was at most of $250^{\circ} \mathrm{C}$ [14]. Recent development efforts focus on achieving temperatures above $650^{\circ} \mathrm{C}$ by increasing the irradiance exposure time [14].

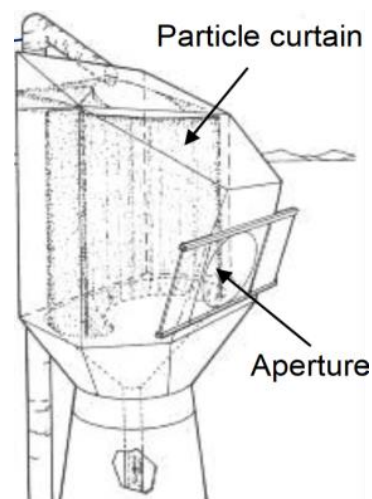

Figure 4. Free falling particle curtain [26]

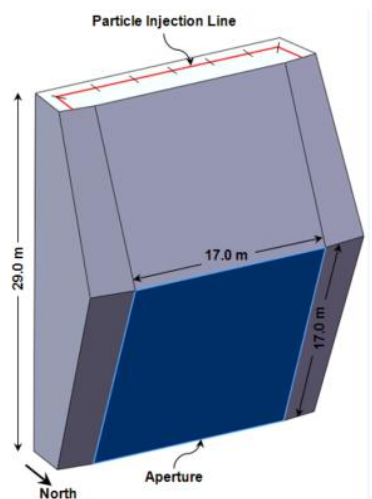

Figure 5. Geometry of particle receiver[20] 
Figure 4 and Figure 5 show the proposed geometry. Particles inside the receiver are heated by concentrated sunlight which enters the receiver from an aperture on the bottom.

This system uses spherical solid particles that serve as HTF as well as TES media [24]. With this approach, temperatures can theoretically go over $1000{ }^{\circ} \mathrm{C}$ without changing chemically the material; also potentially high receiver efficiency can be reached due to direct solar absorption. Using low cost solid particle materials can reduce significantly TES costs, by storing heat at higher temperatures. Free falling receiver seems to be adequate for $10-100 \mathrm{MWe}$ power-tower CSP systems [20].

Several tests have been made on the more advanced prototype for evaluating outlet power and temperature for free-fall and obstructed-fall designs [27]. Also, Siegel et al. [35] performed tests to evaluate the velocity distribution and concentration of the material over the particle curtain. The prototype was tested on Sandia National Laboratories with a $61 \mathrm{~m}$ central receiver with one thousand suns concentration in Albuquerque, NM.

Current research goes through the determination of the effects of the aperture size, tilt and dimension. Additional studies for developing these receivers includes different approaches to increment the residence time of the material in the receiver, and developing an air curtain for receiver aperture [26].

\subsubsection{Particle recirculation}

One way to increase residence time on the Free Falling Particle Receiver is to make the particles pass several times on the aperture for reaching the high temperatures desired [49]. Recirculation has shown, in simulations, to be effective when increasing the particle temperatures above $800^{\circ} \mathrm{C}$. In order to fully understand how the particles flow across the particle receiver, Computational Fluid Dynamics (CFD) models were developed. Several factors are included in the simulations such as solar irradiation, re-radiation and emission from the cavity walls, convection, wall conduction, and two-phase particle/air flow [35].

The strategy is to release colder particles into the locations, within de receiver, where the irradiance is lower, to preheat the particles before going into high irradiated regions [50]. Also, it has shown to reduce heat loss effect caused by external wind. Other variables had been studied, like particle size effect, in order to found their relation with the stability of the recirculation system [26] as shown in Figure 6. In addition, heat transfer coefficient has shown to be directly related to the particle velocity, and particle volume fraction [11].

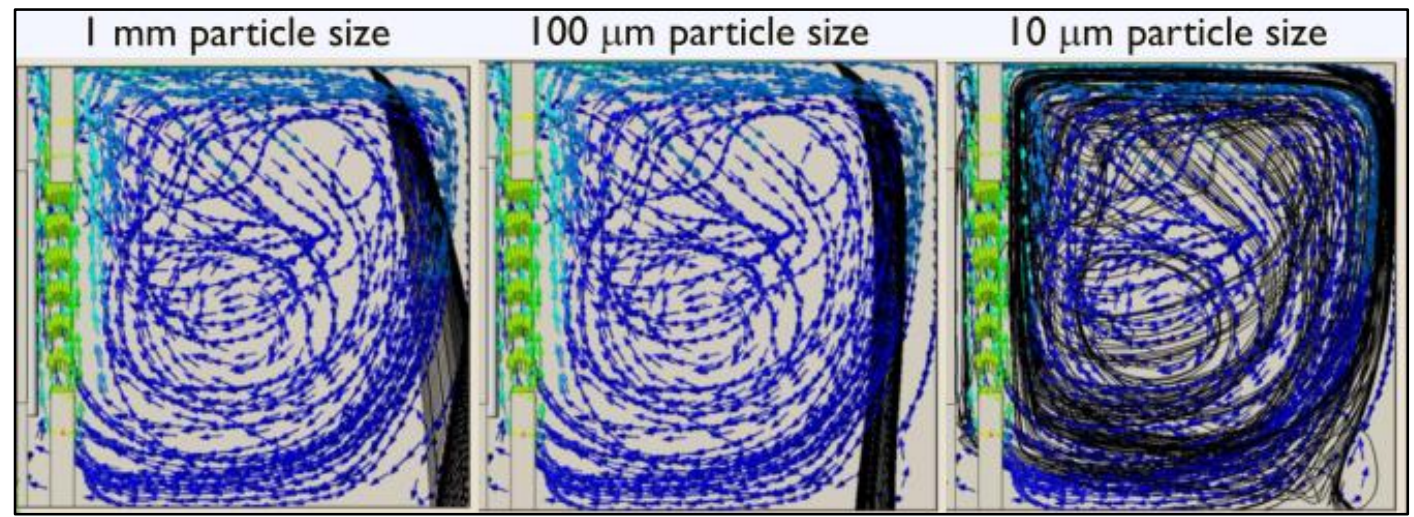

Figure 6. Simulations of the free falling curtain stability impacted by particle size [26] 


\subsubsection{Obstructed particle flow receiver}

As mentioned before, the increase of the irradiance exposure time of the solid particle material is necessary to approach the desired temperature. Another way proposed to do this is to mechanically obstruct the particle flow through the receiver using different kind of obstacles [18]. For this, different options have been proposed:

- Ceramic porous structures. Consists on using porous interconnected structures in which the particles go through by gravity; increasing the falling time of the particles and therefore, increasing the irradiance exposure time. Additionally, the amount of particle attrition due to wind and dispersion is considerably reduced. Small scale tests have already been performed for thousands of cycles [26,50]. Figure 7 shows the morphology of the proposed porous structure. Irradiance uniform distribution on the material flow is important for getting to the desired temperatures when material reaches the hot storage tank. Also, based on the current tests already performed, research for finding a material for the porous structure that can mitigate the deterioration due to the material flow and the high temperature is needed.

- Porcupine structure. This way to increase residence time is based on placing quills inside the receptor that interfere with the particle flow [26]. Figure 8 illustrates this kind of structure. There has been some laboratory scale testing reported for this kind of structure [51] considering different mesh counts. Nevertheless, there are no considerations about the best particle material selection.

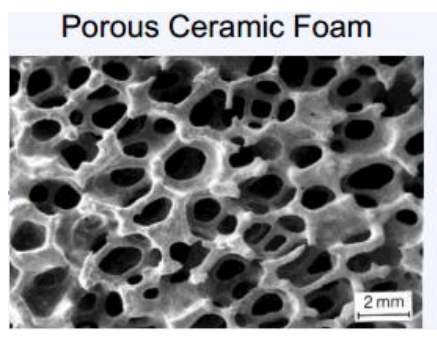

Figure 7. Porous structure SPSR [26].

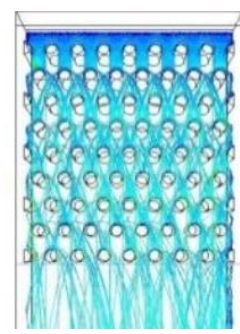

Figure 8. Porcupine structure [26].

Some experimental and simulations evaluation of the different structures considering only the residence time on standard conditions are reported [52]. Also, two kinds of particles have been tested for fluency testing. Nevertheless, no clear analysis and recommendations for material selection has been made.

Finally, several aspects need to be considered about the particle material itself (heat capacity, density, thermal conductivity, etc.) to reach high temperatures on the receiver and not only the system parameters and design.

\subsubsection{Rotating kiln receiver}

Since the first studies of solid particle materials for solar power tower, rotating/centrifugal receiver were proposed [53]. The working principle, shown in Figure 9 is to feed the particles into a rotating kiln which delays the particle fall by using centrifugal force against the kiln walls. These particles are irradiated from the particle outlet aperture [14]. Tests have been made in a $\sim 10 \mathrm{kWth}$ laboratory scale prototype by $\mathrm{Wu}$, et al [40] at different power levels, mass flow and inclinations. Controllability, receiver vibration stability and thermal stability have been proved to be possible at this scale. 
Current research is based on maintaining stable mass flow rate at large scale, minimizing the impact of the energy spent on moving the kiln and reliability on larger receivers [14].

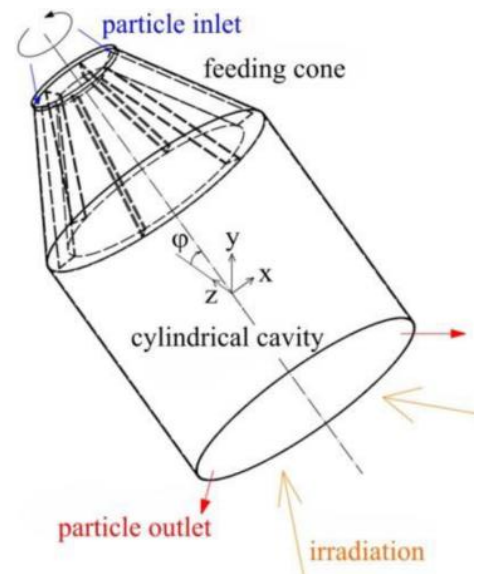

Figure 9. Rotary kiln/centrifugal particle receiver [40].

\subsubsection{Wind effect on open receivers}

Wind effect of solar power towers using open receivers can be considerable due to the height of the tower above the ground (which can be located even at 250 meters above the ground) [24]. Wind speed at those heights is considerable higher that current lab prototype or pilot plant experimental tests at lower altitudes [54].

Constant winds can enter through the radiation aperture producing air convection by the temperature difference with the air inside the receiver, and even ejecting particles from the receiver (Figure 11). Therefore, impact on the overall efficiency of the receiver can be considerably affected. In order to prevent these problems, aerowindows have been proposed. It consists on hot-air jet curtains near the aperture of the receiver produced by a blower, which isolates the inner atmosphere from the outer [38] without having any effect on the optical performance of the receiver. It has been calculated that efficiency can be increased nearly $10 \%$ using this solution depending on wind speed [50].

Several experiments have been performed to evaluate the aerowindow effect. Increasing air speed on the curtain does not necessarily means increasing efficiency, therefore determining the best speed is complex. This effect is caused by the combination of the high speed wind and the air jet, that can produce turbulence inside the cavity [38]. Performance experiments have been carried out at different aerowindow temperatures and air jet speeds, as well as at several external wind speeds. The temperature effect has shown small influence on the overall receiver efficiency [38].

Another solution to get the way around the wind effect is to use a beam-down solar concentrator, in which solar radiation is reflected to the ground while being concentrated, replacing the tower. This concept has been studied for current molten salts systems [55,56], and has been recently tested on a pilot plant in Sicily, Italy [57]. Nevertheless, costs of the high temperature heliostats have not been proved to be lower enough to be viable for real plant implementation.

Finally, other recirculation options have been proposed, such as the suction-recirculation shown in Figure 10. In this approach, part of the HTF material is suctioned from behind the receiver 
and then separated by a cyclone while the air is pumped again to the material entrance of the receiver minimizing the thermal and material loss from the outside [58]. This recirculation is proposed for managing the wind effect, and is not considered or designed for increasing the particle residence time in the receptor.
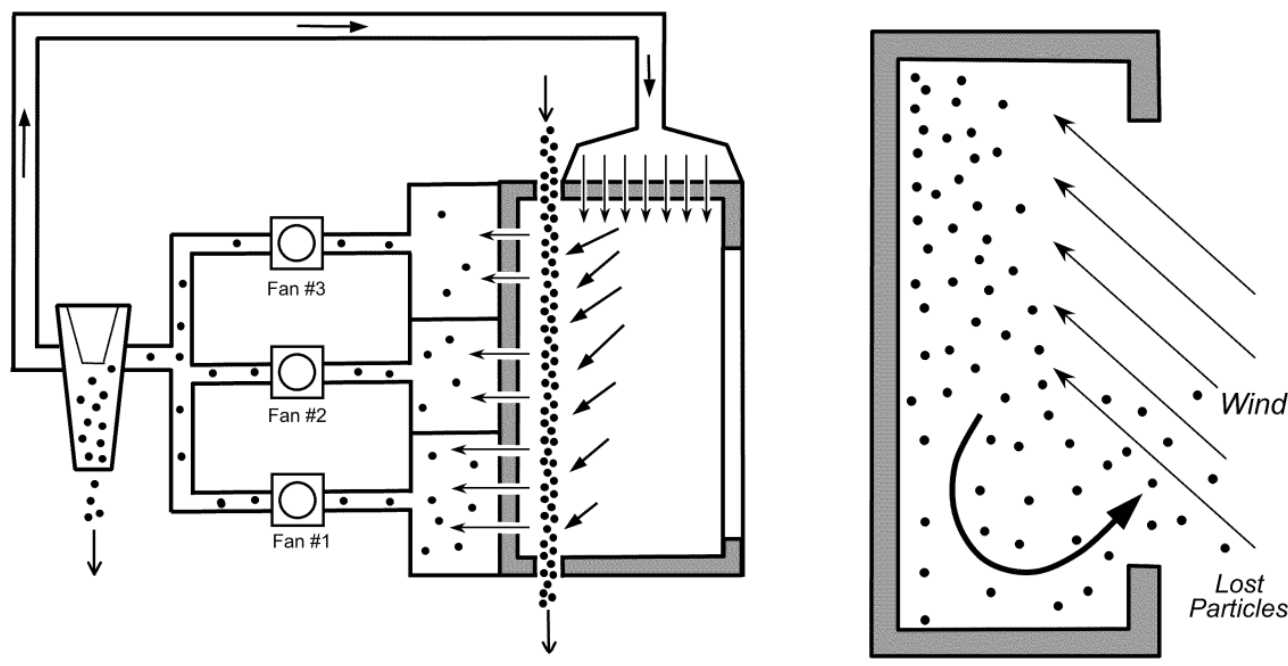

Figure 10. Suction recirculation receiver [58].

Figure 11. Wind effect on the receiver [58].

\subsubsection{Fluidized direct receiver}

This receiver design consists on using fluidization to control mass flow rate and therefore increase de irradiance exposure time. Also, other benefits are that the effects of the wind at the receptor are mitigated.

Several test have been made using single or multiple tube arrays since the 1980s [11,28,53,59]. All of the reported designs and tests have been performed using a quartz tube. Nevertheless, none of them evaluate the influence of the material optical properties on the receiver's efficiency.

Different materials have been evaluated, finding some restrictions for the solid particle material [28]. It was found that a very small particle size lowers efficiency, while too large particles difficult fluidization. Optimal size was found between 0.5 to $1 \mathrm{~mm}$ mean size diameter for cold fluidization, but is expected to change for high temperature [28]. On single tube experiments temperatures have reached to $867{ }^{\circ} \mathrm{C}$, while on multiple tube array has reached $624{ }^{\circ} \mathrm{C}$ [59].

Numerical simulation has been made and was found that heat transfer between air and particles is good, showing differences under $25^{\circ} \mathrm{C}$ [60]. Efficiency calculations showed that when the air flow was higher, the outlet temperature was lower but the efficiency was higher. Also, increasing the input temperature (which will correspond with increasing the solar irradiance) increases the outlet temperature but lowers the efficiency [60]. This behavior contradicts the objective of the whole solid particle CSP concept, which relies on reaching high temperatures to increase the electricity generation cycle efficiency. Therefore, a correct balance between the two efficiencies should be reached in order to make this design viable.

On other experimental tests it was found that a good air flow distribution on the tube reflects on a good overall performance, and that the fluidized states depends also on the temperature difference between the particles and the air [59]. 
Future work for this receiver design should include ways to reduce the thermal loss on the external walls of the tube [60], getting more accurate optical concentrating ratio, improving the design of the air inlet, define the optimal particle parameters on high temperature fluidization and optimize the design of the receiver according to the irradiation area [28].

\subsection{Indirectly irradiated receivers}

Indirect receiver concept relies on using solid particle materials as HTF but use another surface to receive the solar irradiation. This can be convenient for using solid particle materials without a high solar absorptance. Nevertheless, exergy on heat exchange between the surface and the particles must be considered [19].

Two main designs have been proposed for indirect receiver according to their particular principle of work.

\subsubsection{Particle flow integrated with heat exchanger (HEX) receiver}

SunShot CSP program [61] includes the design of another approach for particle receiver. The main objective of this program is to design a high-temperature particle receiver and heatexchanger system, and also build a prototype receiver that can reach a thermal efficiency over $90 \%$, reaching a fluid temperature greater than $650^{\circ} \mathrm{C}$, and particles outlet temperature of $800{ }^{\circ} \mathrm{C}$ [36]. The general concept for the particle receiver is shown in Figure 12.

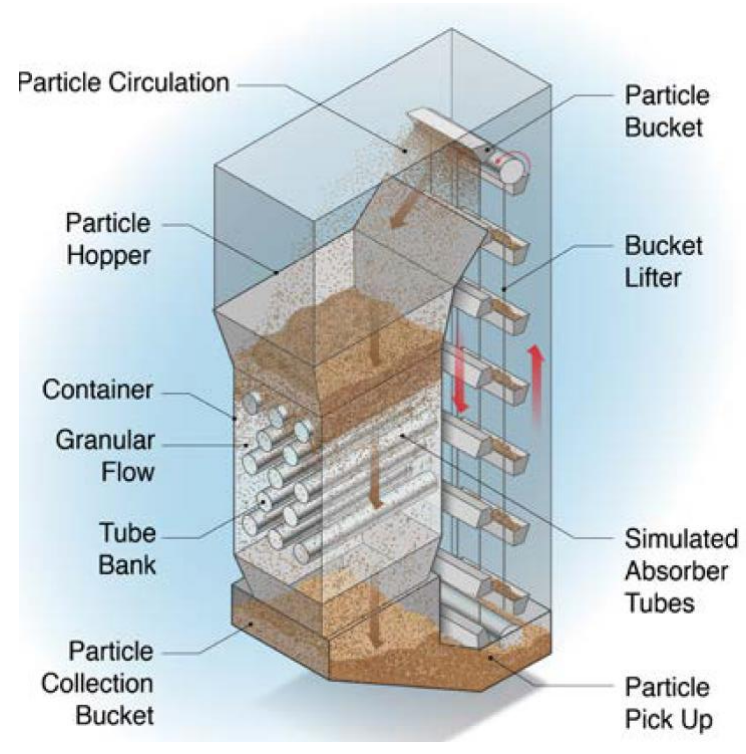

Figure 12. Particle flow with HEX receiver [36]

The work principle of this design is to exchange heat between an array of staggered tubes that receive concentrated sunlight on their interior surface, and the solid particles that flow downward the main receiver enclosure having contact with the exterior surface of the tubes [14].

Also, the SunShot initiative considers a simulation program called Bridge project [62]. This tool brings the fundamentals of heat transfer and material-fluid flow modeling for designing the particle receiver, making the system behavior easy to analyze. Another tool of particular importance for predicting the operation temperature is the Multiphase Flow with Interface eXchanges (MFIX) [62], with which transfer models for solid and fluid phases can be built. 
Another related approach under development uses a two-phase flow as HTF, and solid particles as TES medium. It uses a near-blackbody receiver which transfer the heat to the HTF by an integrated fluidized-bed heat exchanger [37]. The main goal of these initiatives is to get up to 30 years of service life, with an overall cost estimated at less than $\$ 100 / \mathrm{kW}_{\text {th }}$ and with heat storage costs under $\$ 6 / \mathrm{kWh}_{\text {th }}[36]$.

As occurs on directly radiated designs, solid particle material selection plays a minimal role on this approach. Thus, material properties needed to ensure correct heat exchange and good flow thru the system should be taken into the account for future research.

\subsubsection{Fluidized indirect receiver}

This design is very similar to the fluidized direct receiver on work principle. However, the absorptance variable is limited to the material of the tube, extending the possible solid particle candidate materials. The solid particles are forced upward through the irradiated tubes by airflow increasing the heat transfer between the tube walls and the solid particles [14]. Both, single a multiple tube experiments have been reported and compared with fluidized direct receiver $[11,41,53]$.

Using ceramic tubes is possible for this design, and can extend the operating temperature around $1000{ }^{\circ} \mathrm{C}$ with a good efficiency [11]. Also, ceramic tubes can allow a better thermal isolation than quartz improving the efficiency of the receiver. Nevertheless, heat loss can still be considerable and should be reduced. No efficiency has been reported on the experimental or theoretical analysis.

\section{Particle conveyance through the system}

One of the main concerns of particle conveyance is the system used to lift the particles up to the solar collector. Other elements that will carry the material have not been directly reported. Nevertheless, fluidized bed manufacturers and other suppliers have experience on studying erosion and corrosion protections. Tube-bend design, weld overlay and plasma spray coatings have been developed based on ceramic materials [19].

For particle lifting, several technologies are considered such as mine hoists, bucket elevators, pocket elevators, screw conveyors, Olds elevators, pneumatic conveyors, conveyor belts, cleated conveyor belts, metallic belted conveyors, En-masse's elevators, bucket wheels, linear induction motor powered elevators, and electromagnetic field conveyors. Notwithstanding that these technologies are commonly used on mining industry, some of these equipment have been evaluated for temperatures over $800{ }^{\circ} \mathrm{C}$ (Olds elevator, conventional bucket lift, and pocket elevator), to determine their efficiency and performance on the solid particle approach [50].

Mine hoist using insulated containers is considered due to its efficiency in relation to the weight of the material hoisted, and to the possibility to take advantage of the potential energy of the material on the way down from the receiver. Other capable concept is the pocket elevator, in which particles are transported to the receiver by pockets that discharge the material when getting inverted at the top [50].

A possible way to avoid energy expenses and investment on lifting the material up to the tower, as well as the difficulty of placing the receiver at the top of the tower, is to use a the beam-down solar concentrator concept described previously. Another advantage of this technology is to avoid heat losses when the heat transfers from the receiver to the energy converter [56]. 
Finally, there is lack of compatibility analysis between the solid particle materials and the material of which the conveyance system will be made. Therefore, more extensive research an analysis must be made for the long term.

Regarding to sensible heat storage, the solid particle concept needs to be experienced out from lab-scale. The transportation of large masses cause critical parasitic loads which have to be minimized, as well as the mechanical loads of heat exchanger for solids at high temperatures [17]. Also, Investigation of particle elevators that satisfy requirements for flow rate, temperature, and particle retention is needed [26]. In addition, the materials selected will withstand these high temperatures while yielding a receiver cost of less than $\$ 150 / \mathrm{kWh}_{\mathrm{th}}$ [36].

\section{Solid Particle storage}

Two different containers are required for storing solid particles: the first one will contain hot material (at around $800{ }^{\circ} \mathrm{C}$ ) that have just been heated up, while the second one will contain only "warm sand" (at around $350^{\circ} \mathrm{C}$ ) that has been already cooled down by the heat exchanger that powers up the generation cycle $[63,64]$.

Mainly cost aspects motivate the application of solids as heat storage media. The material costs for concrete, per stored energy unit, for example, are in the range of $10-20 \%$ of the corresponding costs for molten salts, and maintenance costs are also expected to be lower for solid media storage systems [12]. The goal of these options is to reduce the path for heat transfer from the bulk of the storage material to the transfer medium [17].

The construction of a well-insulated TES system becomes important in such a high-temperature application because the thermal losses are anticipated to be higher, resulting in more substantial thermal cycling issues. However, the cost of such TES system should be minimized so that operating at higher temperatures can still be economically justified. High-temperature TES systems can be constructed with readily available materials that yet meet the heat-loss requirements for a falling particle receiver system, thereby contributing to reducing the overall cost of concentrating solar power systems [50].

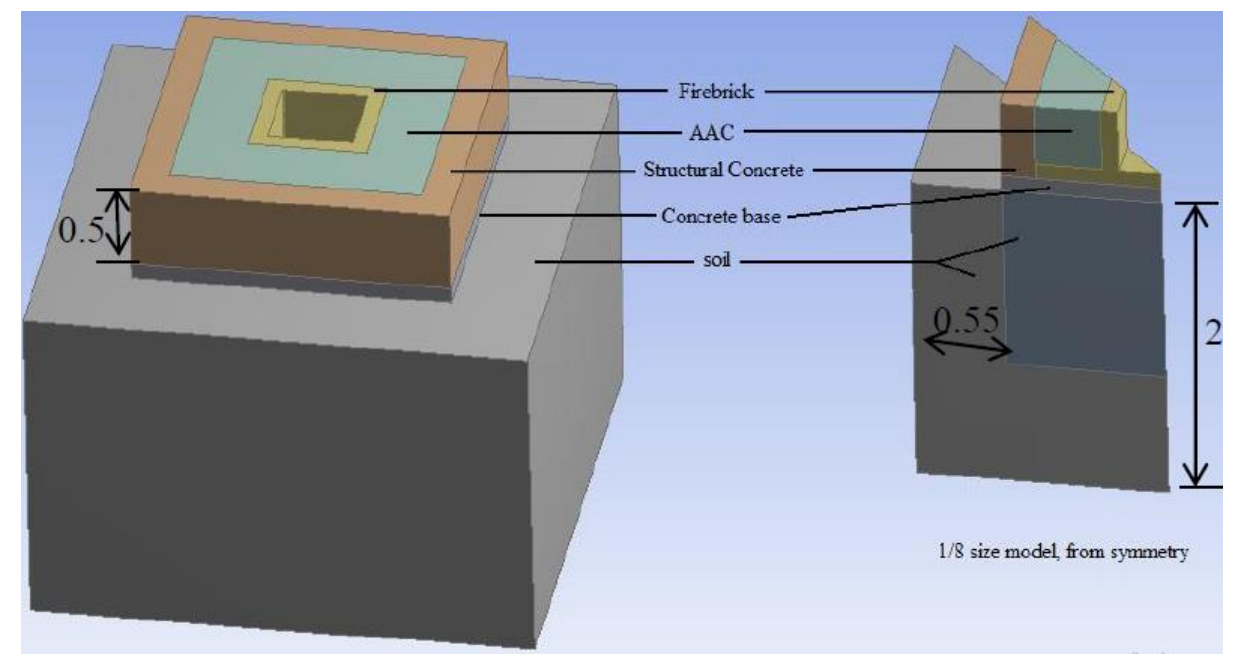

Figure 13. Solid particle TES bin prototype [64]

The tower design bin has several key aspects that require experimental development. The TES bin proposed by Abdelrahman El-Leathy (2014) had a rectangular shape; this shape would not be suitable for large-scale TES bins due to its structural issues, especially at the corners. It was 
determined that a round-shaped TES bin would be a suitable option to pursue and build for continued testing. The prototype, in Figure 13, exhibited superior performance and no degradation of the materials. This design can also be suitable for high-temperature applications other than the falling particle receiver, and further tests will explore the effectiveness of the materials as insulators, particularly at high temperatures, as well as further examining their structural soundness at these elevated conditions [64].

A high temperature lining material is required so that it will be capable of storing the heated material with minimal heat losses while remaining structurally stable. In this regard, a series of high-temperature insulating concretes are being tested. The first was aerated autoclaved concrete (AAC), and the second was perlite concrete (PC). Perlite concrete has been tested in lab-scale furnaces up to $1000^{\circ} \mathrm{C}$ cycles, without cracking or crumbling for approximately 50 hours' worth of exposure. Portland cement-based concretes typically begin to lose strength at temperatures above $300^{\circ} \mathrm{C}$. Despite the durability and low cost of firebrick, its thermal performance was not suitable, due to its high thermal conductivity; AAC is not suitable for use in future designs, due to the issue of cracking caused by high temperatures. Consequently, the investigation with regard to these materials was incorporated in one multiple material wall. Moreover, to ensure proper insulation of the hot bin, it is important to have materials with minimal thermal conductivities and insulating firebrick (IFB) and expansion joint (EJ) are thus considered [64].

On the other hand, TES system using solid graphite modular blocks for CSP plants stores energy at temperatures higher than $800^{\circ} \mathrm{C}$, and is robust enough to withstand the thermal cycles foreseen in a lifespan of 30 years, with no parasitic energy consumption [65]. The graphite material proposed appears to be superior to concrete for use as a TES storage medium. This technology can upgrade the operating range of thermal storage to significantly beyond that of molten salt $\left(1650^{\circ} \mathrm{C}\right.$ vs. $\left.565^{\circ} \mathrm{C}\right)$, which could also have direct application to solar power towers.

The usable TES storage capacity is derived from multiplying the design point power-cycle thermal load by the required hours of thermal storage, and it is rated with power-cycle

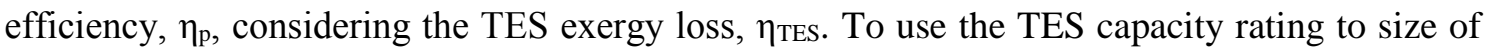
the physical dimensions of the storage system, one must calculate the heat capacity, density, and distribution of all active storage materials [19].

As occurred on other parts of the solid particle CSP system proposed, there must be more research of the particle material itself. The effect of density stratification, sintering and agglomeration resistance and particle size stratification must be considered for future work. Also, possible solid-solid phase changes could occur to some materials changing the density and heat properties between the two different storage tanks or even at one same tank if there is considerable temperature gradient stratification.

Cost-effective solid storage materials show low thermal conductivities representing the main challenge for the implementation of an effective storage concept [12].

Storage systems are being investigated at two different levels: on the one hand, the interaction of storage units with the other components of a CSP plant; on the other hand, storage concepts aims at cost reduction by more efficient material usage based on an improved understanding of the heat transfer processes in the storage system [17]. Also storage systems must be planned specifically for CSP SPT application, inasmuch as the systems commonly proposed were made for other industries. 
Further development of existing storage concepts deal with capital costs in the range of 35-50 $€ / \mathrm{kWh}_{\mathrm{th}}$, or even more because of the increase of efficiency due to high temperature generation cycles considered for solid particles approach. Two-tank molten salt systems provide a benchmark for acceptable investment costs for sensible heat storage concepts. Various aspects should be considered here: costs should only be compared for systems with the same temperature range, identical discharge duration and the same storage time [17]. Other research efforts need to be made related to testing of prototype thermal storage bins using new geometries [26].

\section{Heat exchanger between solid particles and the electricity generation cycle}

For using solid particles as HTF, the most deeply investigated heat exchanger is the fluidized bed-CSP system (FB-CSP) [19,21,66]. FB-CSP uses two phases gas-solid flow to replace liquid salt or oil as HTF, and allows using the solid phase as storage. The thermal system implemented in FB uses sensible heat of solid particles for thermal energy storage, besides it has the ability to integrate latent and thermochemical storage [21].

FB-CSP operation is composed of a hot storage tank connected to the solar receiver output. In this configuration, solid particles are introduced to the heat exchanger in order to transfer energy following conventional configuration. The cooled particles that exit the heat exchanger are sent to the cold storage tank pumped by mechanical force, pneumatic force or gravity force [11].

In order to ensure a desired efficiency in the FB-CSP, some parameters must be controlled: maximize the heat transfer between the solids and the heating surface, guarantee a stable fluidization by means of operating as close to the minimum fluidization conditions, and the particles selected have to accomplish certain requirements such as performance of fluidization and flowability. Schwaiger et al. [66] modeled and analyzed costs and challenges for an active FB (called by the authors SandTES).

The efficiencies to be considered in the heat exchanger fluidized bed in terms of TES performance metrics are: storage effectiveness and first law and second law efficiencies [21]. The storage effectiveness accounts for usable storage out of the gross TES media load, and can also be denominated as the discharge efficiency or the storage fraction [67]. The implementation of solid particles-TES in the FB-CSP can lead to a $100 \%$ storage effectiveness [19]. The first law and the second law of efficiency describe the losses in terms of heat and energy conservation (exergy), respectively, during charging and discharging process. Zhiwen et al. [19] and Z.Ma et al. [21] established the equations for the corresponding efficiencies defined above.

A major cause of exergy losses in CSP systems is any place in a system where heat transfer from one fluid to another occurs, usually in a heat exchanger. Major areas of heat exchange in CSP systems can include:

- From HTF to storage medium

- From HTF to power cycle working fluid

- From storage medium to power cycle working fluid

- From power cycle working fluid to ambient air (condenser or cooling tower).

Figure 1 shows the main scheme of a particle TES with FB (Fluidized Bed) heat exchanger integrated in a CSP plant with a tower solar field. The integrated FB-CSP system can drive different power generation cycles, including a Rankine power cycle, or a high-efficiency supercritical carbon dioxide (s- $\left.\mathrm{CO}_{2}\right)$-Brayton power cycle $[21,31,68]$. 
Heat exchangers suitable for coupling particulate media to process fluids such as pressurized air and steam have been developed in the past [34]. However, many of these systems have not been evaluated and optimized for the temperatures, particle materials, and flow rates being considered for high-temperature falling particle receivers. Other aspect that must be evaluated is the possible variation of the shape and mean size of the material over time and caused by the thousands of thermal cycles expected.

\section{Challenges}

The development of the solid particle technologies for sensible heat storage at high temperatures for using con solar power tower CSP has three main challenges. The first one related to the complete integration of all concepts. Several studies and developments are under way but not all the functional units are equally developed; for example, lack of studies on particle conveyance are not clearly reported even that it could affect critically the complete energy balance of the plant. Only on complete pilot plant some integration studies have been made, but are mainly focused on the receiver concept. With a complete plant integration analysis, possible conflicting working requirements can be detected and avoided. The second type of challenge requires that each functional part of the concept should be proven enough to achieve commercial viability. The main aspects to develop the technology are summarized on Table 1. This summary can help not only new researchers in the area to fulfil the main gaps of the current technology, but also people working in other areas with similar challenges to implement them in that technology. Finally, it is the current picture with the know-how updated details.

\begin{tabular}{|c|c|c|}
\hline $\begin{array}{c}\text { Functional } \\
\text { part }\end{array}$ & Challenges & Current Research \\
\hline $\begin{array}{l}\text { Open direct } \\
\text { receivers }\end{array}$ & $\begin{array}{l}\text { - Increase residence time. } \\
\text { - Improve materials used for slowing } \\
\text { flow structures. } \\
\text { - Research for optimal solid particle } \\
\text { materials for improving absorptance } \\
\text { efficiency. } \\
\text { - Study material compatibility of } \\
\text { solid particles and material of the } \\
\text { system itself. } \\
\text { - Convective and radiant heat losses } \\
\text { problems must be solved. }\end{array}$ & $\begin{array}{l}\text { - Increase residence time and the } \\
\text { effect on the receiver efficiency. } \\
\text { - Prototype testing is under way } \\
\text { looking for best geometries. } \\
\text { - Energy balance and CFD for air } \\
\text { curtain and particle recirculation are } \\
\text { being enhanced. }\end{array}$ \\
\hline $\begin{array}{l}\text { Closed direct } \\
\text { receivers }\end{array}$ & $\begin{array}{l}\text { - Increase residence time. } \\
\text { - Study possible thermal losses on } \\
\text { the tube due to the optical properties. } \\
\text { - Study parasitic energy } \\
\text { requirements due to the fluidization. } \\
\text { - Make pilot plant scale testing. } \\
\text { - Work on enhancing the thermal } \\
\text { isolation of the tube. } \\
\text { - Poor heat transfer. Low } \\
\text { conductivity in the particle side. }\end{array}$ & $\begin{array}{l}\text { - Define desired properties of } \\
\text { particles for fluidization on high } \\
\text { temperature. } \\
\text { - Optimize the design of the } \\
\text { receiver according to the irradiated } \\
\text { area. } \\
\text { - Improve air intake according to } \\
\text { particle size distribution. }\end{array}$ \\
\hline $\begin{array}{l}\text { Indirect } \\
\text { receivers }\end{array}$ & $\begin{array}{l}\text { - Increase residence time. } \\
\text { - Define desired properties of } \\
\text { particles for fluidization. } \\
\text { - Study parasitic energy } \\
\text { requirements due to the fluidization. }\end{array}$ & $\begin{array}{l}\text { - Exergy analysis on the heat } \\
\text { exchange to the solid particles and } \\
\text { according to the design used. } \\
\text { - Define desired properties of } \\
\text { particles for fluidization on high }\end{array}$ \\
\hline
\end{tabular}




\begin{tabular}{|c|c|c|}
\hline & $\begin{array}{l}\text { - Work on enhancing the thermal } \\
\text { isolation of the tube. } \\
\text { - Maintain a uniform particle } \\
\text { concentration and temperature. } \\
\text { - Improve thermal isolation to } \\
\text { decrease potential thermal loss. }\end{array}$ & $\begin{array}{l}\text { temperature. } \\
\text { - Optimize the design of the } \\
\text { receiver according to the irradiated } \\
\text { area. } \\
\text { - Improve air intake according to } \\
\text { particle size distribution. }\end{array}$ \\
\hline $\begin{array}{c}\text { Conveyance } \\
\text { system }\end{array}$ & $\begin{array}{l}\text { - Material compatibility needed for } \\
\text { assuring long term durability, } \\
\text { especially on the particle lifting } \\
\text { systems. } \\
\text { - Research for using potential energy } \\
\text { lost when particles go down from the } \\
\text { receiver. }\end{array}$ & $\begin{array}{l}\text { - Use technologies already } \\
\text { developed for particle materials and } \\
\text { adapt them to the current needs. } \\
\text { - Study of the parasitic charges } \\
\text { related to the large masses of } \\
\text { material that are expected to be } \\
\text { moved. }\end{array}$ \\
\hline Storage tanks & $\begin{array}{l}\text { - Reach investment costs lower than } \\
35 € / \mathrm{kW}_{\text {th. }} \\
\text { - Consider and evaluate changes on } \\
\text { the solid particle material, such as } \\
\text { variations on mean size and size } \\
\text { distribution through the plant } \\
\text { lifetime. } \\
\text { - Study designs for avoiding particle } \\
\text { agglomeration and sintering. } \\
\text { - Evaluate the impact of density } \\
\text { and/or temperature stratification } \\
\text { inside de tanks. }\end{array}$ & $\begin{array}{l}\text { - Tank built materials durability on } \\
\text { the long term. } \\
\text { - Adequate thermal isolation to } \\
\text { minimize energy loses. } \\
\text { - Interaction of the storage elements } \\
\text { with the rest of the CSP plant. } \\
\text { - Study of efficiency and durability } \\
\text { of different tank geometries. }\end{array}$ \\
\hline $\begin{array}{c}\text { Heat } \\
\text { exchanger }\end{array}$ & $\begin{array}{l}\text { - Enhance heat transfer coefficients. } \\
\text { - Evaluate particle changes during } \\
\text { plant lifetime and due to temperature } \\
\text { change over the exchanger (like } \\
\text { possible allotropic changes). } \\
\text { - Integrate parasitic loads on the } \\
\text { energy balance. }\end{array}$ & $\begin{array}{l}\text { - Improve fluidization stability. } \\
\text { - Study of particle requirements. }\end{array}$ \\
\hline
\end{tabular}

Table 1. System challenges and current research

Finally, the third challenge is about selecting the optimal materials for using as solid particles and for building the system itself. Some materials have been suggested and compared but no proper search, selection and evaluation has been made. This is important because there are few materials that can be used on these conditions and the absence of optimal materials could seriously jeopardize the current developments. In relation to suitable particles, the desirable properties reported are associated with [26]:

- Complete optical characterization of particles

- Development of new formulation for increased solar absorptivity

- Identify methods to mitigate abrasion and attrition

\section{Current research}

Nowadays, the new concept of dense suspension of particles receiver (DSPR) purposed by Flamant and Hemati (2010), is expected to reach suspension temperatures up to $750^{\circ} \mathrm{C}$ for metallic tubes. The particle velocity and the particle volume fraction are the main parameters influencing the heat transfer coefficient. The higher the particle velocity, the higher the heat transfer coefficient, because the particle agitation increases, thus improving the particle movement and the exchange between the wall and the tube center [11]. 
Another line of research lies in the particle receiver modeling [69] in order to optimize the optical particle properties for a high temperature solar particle receiver. It consists of a nonhomogeneous slab of particle dispersion composed of two-layers at high temperature, submitted to a concentrated and collimated solar radiation flux with a reflective receiver back wall as shown in Figure 14:

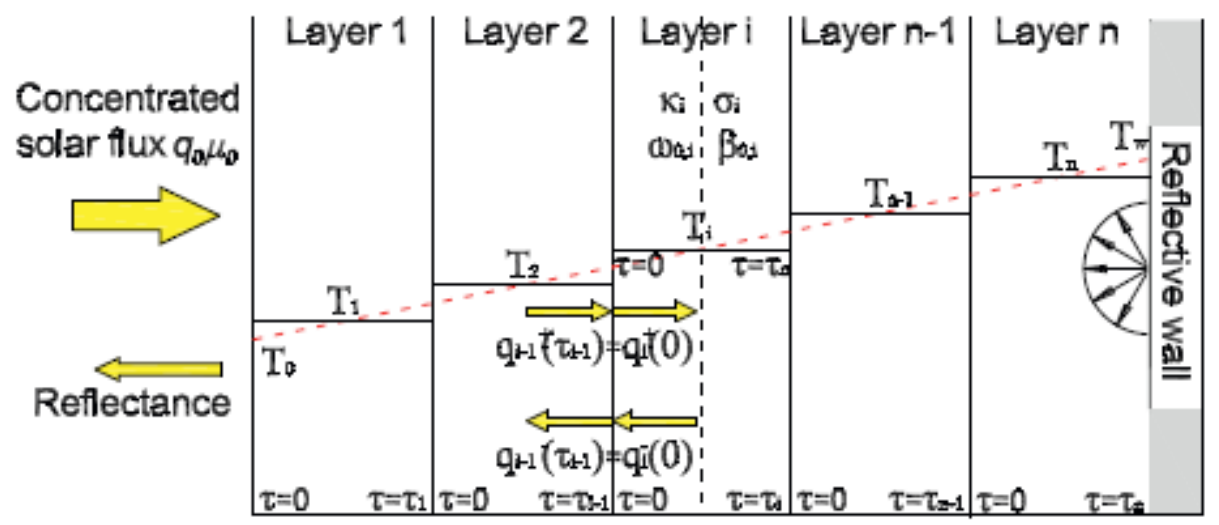

Figure 14. Schematic of a multi-layer solar particle receiver [69]

The research on a particle receiver composed of two layers with the same thicknesses has been optimized according to the volume fraction. The optimization is conducted for both constant and linear temperature profiles. There is no benefit in using different particle sizes in each layer because the receiver temperature is uniform. The optical thickness of this first layer is so large that it has no effect on the second layer efficiency [69].

Falling particle receiver development is focused on enhancing the receiver by means of [26]:

- Conduct optimization of receiver efficiency using CFD models.

- Perform tests with prototype receiver to investigate proposed enhancements .

- Continue evaluation of flow through porous media for increased residence time and particle heating.

Additional improvements are being sought, and features that are being evaluated and optimized include aperture size, nod angle, alternative geometries, particle flow rate per unit length (opacity), particle size, release location, and inclusion of an air curtain [50].

Parameters such as particle-drop position, particle size, particle mass flow rate, and solar input power are under evaluation. Other interactions should be investigated to determine an optimized design [35].

Computational fluid dynamics models of the falling particle receiver have been developed to assist in predicting the performance of these systems. Recent studies are aimed at advancing solid particle receiver technology that will improve the performance and efficiency through the development of novel features and components (e.g., recirculation, increased residence time, solid/fluid heat exchangers, storage, fluidized bed, particles) [18].

The solid particle receiver is now being investigated in multiple configurations, as a technology that could enable lower cost, dispatchable solar power production including 15 hours of thermal energy storage. Combining a mature SPR with an advanced power cycle has several possible benefits including higher efficiency operation and inexpensive, non-corrosive storage media [43]. 
Indirect particle receivers are planned to take the novel approach of using stable, inexpensive materials for the high-temperature receiver, energy storage, structure, and containment. Successful development of the proposed near black body (NBB) receiver and fluidized-bed heat exchanger would achieve high thermal efficiency and higher operating temperatures, and could significantly reduce CSP thermal system capital and operation costs. When integrated with SunShot initiative, solar collectors and power cycles, the combined system is expected to achieve a levelized cost of energy of $\$ 0.06 / \mathrm{kWh}_{\text {th }}[61]$.

There is also a modeling tool that is being used for design of particle receiver to understand and predict the heat transfer in solid flows, including radiation, which is called Discrete Element Model [62].

Table 1 summarizes and compares all the information available for the whole plant concept. Notice that receivers are the main plant part developed at this time.

\section{Conclusions}

A resurgence of solid-particle receivers is occurring as corrosion and material interaction appears favorable for this approach. However, particle conveyance, attrition, and transport remain a challenging prospect.

For now, solid particle CSP TES systems are not commercially available. Several issues must be developed in order to make it a reality. Nevertheless, after about 20 years of standstill, there have been big breakthroughs on the last years. The operating conditions and parameters make this technology especially attractive for today's world energetic context.

The present review condenses all the available information and classifies them considering the main functional parts and remarking the current research in that part as well as the future challenging issues (see Table 1).

Solar receivers are the driver on the development of the technology, compared with the rest of the elements of the plant sections. The following years real tests must be performed in order to reach the next step out of lab-scale. Also, there are concerns that need to be more profoundly developed, such as storage bin materials and particle conveyance systems.

Important issues include increasing the heating of the particles in the receiver while mitigating heat losses. In addition, the design of balance-of-plant components specific to particle heating, exchange, and storage is necessary to enable a working particle receiver system. These include: (1) advances in receiver design with consideration of particle recirculation, air recirculation, and interconnected porous structures; (2) advances in particle materials to increase the solar absorptivity and durability; and (3) advances in the balance-of-plant for falling particle receiver systems including thermal storage, heat exchange, and particle conveyance.

Many properties have been evaluated on previous studies for choosing the optimum material to be used as solid particles for TES. Nevertheless, there is lack of studies that consider most of all the relevant properties in a single evaluation. For this, we must consider environment conditions and a specific kind of system, defined by the particle receiver, heat exchanger, conveyance system and storage bins. Finally, there are different forms for measuring one single property and methodologies and accuracy of results should be considered prior comparing results. Hence we must define which method is more suitable according to the ranges and conditions of the samples. 


\section{Acknowledgements}

The authors would like to acknowledge the Catalan Government for the quality accreditation given to the research group DIOPMA (2014 SGR 1543). The research leading this project has received funding from the European Commission Seventh Framework Programme (FP/20072013) under Grant agreement N ${ }^{\circ}$ PIRSES-GA-2013-610692 (INNOSTORAGE) and from the European Union's Horizon 2020 research and innovation programme under grant agreement No 657466 (INPATH-TES). This work has been partially funded by the Spanish government (ENE2015-64117-C5-1-R (MINECO/FEDER) and ENE2015-64117-C5-2-R (MINECO/FEDER)). Dr. Barreneche would like to thank Spanish Government for the Juan de la Cierva post-doc fellowship 2014 (FJCI-2014-22886). Alejandro Calderón would like to thank Conacyt from Mexico Government to support his research fellowship.

\section{References}

[1] Ge Z, Li Y, Li D, Sun Z, Jin Y, Liu C, et al. Thermal energy storage: Challenges and the role of particle technology. Particuology 2014;15:2-8.

[2] International Energy Agency. Technology Roadmap - Concentrating Solar Power 2010.

[3] International Renewable Energy Agency. Renewable Capacity Statistics 2016.

[4] Trieb F, Schillings C, O'Sullivan M, Pregger T, Hoyer-Klick C. Global Potential of Concentrating Solar Power. SolarPaces Conf. Berlin, Berlin: SolarPaces Conference; 2009.

[5] International Energy Agency. World energy Statistics 2016.

[6] International Renewable Energy Agency. Roadmap for a Renewable Energy Future 2016.

[7] Janjai S, Laksanaboonsong J, Seesaard T. Potential application of concentrating solar power systems for the generation of electricity in Thailand. Appl Energy 2011;88:49607.

[8] Guney MS. Solar power and application methods. Renew Sustain Energy Rev 2016;57:776-85.

[9] Zhang HL, Baeyens J, Degrève J, Cacères G. Concentrated solar power plants: Review and design methodology. Renew Sustain Energy Rev 2013;22:466-81.

[10] Tian Y, Zhao CY. A review of solar collectors and thermal energy storage in solar thermal applications. Appl Energy 2013;104:538-53.

[11] Flamant G, Gauthier D, Benoit H, Sans J-L, Garcia R, Boissière B, et al. Dense suspension of solid particles as a new heat transfer fluid for concentrated solar thermal plants: On-sun proof of concept. Chem Eng Sci 2013;102:567-76.

[12] Lovegrove K, Pye J. Fundamental principles of concentrating power (CSP) systems. Elsevier; 2012.

[13] Gil A, Medrano M, Martorell I, Lázaro A, Dolado P, Zalba B, et al. State of the art on 
high temperature thermal energy storage for power generation. Part 1 -Concepts, materials and modellization. Renew Sustain Energy Rev 2010;14:31-55.

[14] Ho CK. 6 - A new generation of solid particle and other high-performance receiver designs for concentrating solar thermal (CST) central tower systems. Adv. Conc. Sol. Therm. Res. Technol., 2017, p. 107-28.

[15] Nunes VMB, Queirós CS, Lourenço MJ V, Santos FJ V, de Castro CA. Molten salts as engineering fluids - A review: Part I. Molten alkali nitrates. Appl Energy 2016;183:60311 .

[16] Bauer T, Pfleger N, Breidenbach N, Eck M, Laing D, Kaesche S. Material aspects of Solar Salt for sensible heat storage. Appl Energy 2013;111:1114-9.

[17] Steinmann W-D. Thermal energy storage systems for concentrating solar power (CSP) plants. Elsevier. Book: Concentrating solar power technology, 362-394, 2012.

[18] Ho CK, Iverson BD. Review of high-temperature central receiver designs for concentrating solar power. Renew Sustain Energy Rev 2014;29:835-46.

[19] Ma Z, Glatzmaier G, Mehos M. Fluidized Bed Technology for Concentrating Solar Power With Thermal Energy Storage. J Sol Energy Eng 2014;136:31014.

[20] Ho CK. High Temperature Falling Particle Receiver. Sunshot CSP R\&D FOA Ward Recip n.d. http://energy.sandia.gov/wp/wpcontent/gallery/uploads/8_Falling_Particle_Receiver_SunShot_FOA_poster_2012_v3.pd $\mathrm{f}$ (accessed January 10, 2015).

[21] Ma Z, Glatzmaier GC, Mehos M. Development of Solid Particle Thermal Energy Storage for Concentrating Solar Power Plants that Use Fluidized Bed Technology. Energy Procedia 2014;49:898-907.

[22] Hellmann JR, McConnell VS. Characterization of spherical ceramic particles for solar thermal transfer media: A market survey. 1986.

[23] Hellman JR, Eathough MO, Hlava PF, Mahoney AR. Evaluation of spherical ceramic particles for solar thermal transfer media. Sandia Report. 1987.

[24] Siegel N, Kolb G. Design and on-sun testing of a solid particle receiver prototype. 2008 Proc. 2nd Int. Conf. Energy Sustain. ES 2008, 2, 329-34.

[25] Falcone PK, Noring JE, Hackett CE. EVALUATION AND APPLICATION OF SOLID THERMAL ENERGY CARRIERS IN A HIGH TEMPERATURE SOLAR CENTRAL RECEIVER SYSTEM. Proc. Intersoc. Energy Convers. Eng. Conf., 1982, 3, 1498-503.

[26] Ho CK. High Temperature Falling Particle Receiver. SunShot CSP Progr Rev 2013 2013. http://energy.gov/sites/prod/files/2014/01/f7/csp_review_meeting_042413_ho.pdf.

[27] Ho CK, Christian J, Yellowhair J, Jeter S, Golob M. Highlights of the High-Temperature Falling Particle Receiver Project: 2012 - 2016, n.d.

[28] Wang F, Bai F, Wang T, Li Q, Wang Z. Experimental study of a single quartz tube solid particle air receiver. Sol Energy 2016;123:185-205.

[29] Romero Manuel; González-Aguilar J. Solar thermal CSP technology. Wiley Interdiscip Rev Energy Environ 2014;3.

[30] Dunham MT, Iverson B. High-Efficiency Thermodynamic Power Cycles for 
Concentrated Solar Power Systems. BYU Sch 2014;30:758-70.

[31] Wagner MJ, Newman AM, Hamilton WT, Braun RJ. Optimized dispatch in a firstprinciples concentrating solar power production model. Appl Energy 2017;203:959-71.

[32] Padilla R V, Soo Too YC, Benito R, Stein W. Exergetic analysis of supercritical CO2 Brayton cycles integrated with solar central receivers. Appl Energy 2015;148:348-65.

[33] Broome ID, Miller F. Design and analysis of a multi-window aperture structure for a small particle solar receiver. 9th Annu. Int. Energy Convers. Eng. Conf. IECEC 2011, 2011.

[34] Bertocchi R, Karni J, Kribus A. Experimental evaluation of a non-isothermal high temperature solar particle receiver. Energy 2004;29:687-700.

[35] Ho CK, Khalsa SS, Siegel NP. Modeling On-Sun Tests of a Prototype Solid Particle Receiver for Concentrating Solar Power Processes and Storage. ASME 2009 3rd Int. Conf. Energy Sustain. Vol. 2, vol. 2, ASME; 2009, 543-50.

[36] Ma Z. NREL Particle Receiver Will Enable High-Temperature CSP. Natl Renew Energy Lab n.d. http://www.nrel.gov/docs/fy14osti/62504.pdf

[37] Ma Z (National REL. Particle Receiver Integrated with Fluidized Bed. US Dep Energy 2012. http://energy.gov/sites/prod/files/2014/01/f7/55454.pdf (accessed January 26, 2015).

[38] Tan T, Chen Y. Review of study on solid particle solar receivers. Renew Sustain Energy Rev 2010;14:265-76.

[39] Miller F. Small-Particle Solar Receiver for High-Temperature Brayton Power Cycles. San Diego State Univ n.d. http://energy.gov/sites/prod/files/2014/01/f7/55459.pdf (accessed January 27, 2015).

[40] Wu W, Amsbeck L, Buck R, Uhlig R, Ritz-Paal R. Proof of Concept Test of a Centrifugal Particle Receiver. Energy Procedia 2014;49:560-8.

[41] Perez Lopez I, Benoit H, Gauthier D, Sans JL, Guillot E, Mazza G, et al. On-sun operation of a $150 \mathrm{kWth}$ pilot solar receiver using dense particle suspension as heat transfer fluid. Sol Energy 2016;137:463-76.

[42] Alonso E, Romero M. Review of experimental investigation on directly irradiated particles solar reactors. Renew Sustain Energy Rev 2015;41:53-67.

[43] Siegel N, Gross M, Ho C, Phan T, Yuan J. Physical Properties of Solid Particle Thermal Energy Storage Media for Concentrating Solar Power Applications. Energy Procedia 2014;49:1015-23.

[44] Martin J, Vitko JJ. ASCUAS: a solar central receiver utilizing a a solid thermal carrier. Livermore (CA): 1982.

[45] Hurby J, Steele B, Burolla V. Solid particle receiver experiments: radiant heat test. 1984.

[46] Falcone P, Noring J, Hurby J. Assessment of a solid particle receiver for a high temperature solar central receiver system. 1985.

[47] Evans G, Houf W, Greif R, Crowe C. GAS-PARTICLE FLOW WITHIN A HIGH TEMPERATURE SOLAR CAVITY RECEIVER INCLUDING RADIATION HEAT TRANSFER. J Sol Energy Eng Trans ASME 1987;109. 
[48] Hurby J, Steele B. A solid particle central receiver for solar-energy. Chem Eng Prog 1986;82:44-7.

[49] Diver R SL. Serpentine Solar Particle Reciver. 2006.

[50] Ho C, Christian J, Gill D, Moya A, Jeter S, Abdel-Khalik S, et al. Technology Advancements for Next Generation Falling Particle Receivers. Energy Procedia 2014;49:398-407.

[51] Khayyat AW, Knott RC, Nguyen CL, Golob MC, Abdel-Khalik SI, Jeter SM, et al. Measurement of Particulate Flow in Discrete Structure Particle Heating Receivers 2015:V001T05A020.

[52] Lee T., Lim S., Shin S., Sadowski DL., Abdel-Khalik SI., Jeter SM., et al. Numerical simulation of particulate flow in interconnected porous media for central particle-heating receiver applications. Sol Energy 2015;113:14-24.

[53] Flamant G. Theoretical and experimental study of radiant heat transfer in a solar fluidized bed receiver. AIChE J 1982;28:529-35.

[54] Peterson EW, Hennessey JP. On the Use of Power Laws for Estimates of Wind Power Potential. J Appl Meteorol 1978;17:390-4.

[55] Li X, Dai YJ, Wang RZ. Performance investigation on solar thermal conversion of a conical cavity receiver employing a beam-down solar tower concentrator. Sol Energy 2015;114:134-51.

[56] Wei X, Lu Z, Yu W, Xu W. Ray tracing and simulation for the beam-down solar concentrator. Renew Energy 2013;50:161-7.

[57] Wöhlbier RH. Magaldi: The first STEM (Solar Thermo Electric Magaldi) plant starts operations in Sicily. Bulk-Online, The Powder/Bulk Portal 2016. http://blog.bulkonline.com/news-english/magaldi-the-first-stem-solar-thermo-electric-magaldi-plantstarts-operations-in-sicily.html (accessed January 1, 2017).

[58] Kolb GJ. Suction-recirculation device for stabilizing particle flows within a solar powered solid particle receiver. US8109265 B1, 2012.

[59] Bai F, Zhang Y, Zhang X, Wang F, Wang Y, Wang Z. Thermal performance of a quartz tube solid particle air receiver. Energy Procedia, vol. 49, 2013, p. 284-94.

[60] Wang F, Bai F, Wang Z, Zhang X. Numerical Simulation of Quartz Tube Solid Particle Air Receiver. Energy Procedia, vol. 69, 2015, p. 573-82.

[61] Project Profile: Particle Receiver Integrated with a fluidized bed. US Dep Energy n.d. http://energy.gov/eere/sunshot/project-profile-particle-receiver-integrated-fluidized-bed (accessed January 26, 2015).

[62] Hrenya C (University of C, Ma Z (National REL, Morris A (University of C, Pannala S (ORNL), O'Brien T (NETL). Using Solid Particles as Heat Transfer Fluid for use in Concentrating Solar Power (CSP) Plants. DOE CSP Progr Rev 2013. http://energy.gov/sites/prod/files/2014/01/f7/csp_review_meeting_042413_ma2.pdf

[63] Jeter S, Sadowski D, Golob M, McKoy J, Stephens J, Lines B. Development of a novel thermal energy storage system using sand as the medium. 39th ASES Natl. Sol. Conf. 2010, 2, 1279-85.

[64] El-Leathy A, Jeter S, Al-Ansary H, Abdel-Khalik S, Roop J, Golob M, et al. Thermal 
Performance Evaluation of Two Thermal Energy Storage Tank Design Concepts for Use with a Solid Particle Receiver-Based Solar Power Tower. Energies 2014;7:8201-16.

[65] Project Profile: High-Efficiency Thermal Storage System for Solar Plants. US Dep Energy n.d. http://energy.gov/eere/sunshot/project-profile-high-efficiency-thermalstorage-system-solar-plants (accessed January 27, 2015).

[66] Schwaiger K, Haider M, Hämmerle M, Wünsch D, Obermaier M, Beck M, et al. sandTES - An Active Thermal Energy Storage System based on the Fluidization of Powders. Energy Procedia 2014;49:983-92.

[67] Yang Z, Garimella S V. Molten-salt thermal energy storage in thermoclines under different environmental boundary conditions. Appl Energy 2010;87:3322-9.

[68] Sakadjian B, Hu S, Maryamchik M, Flynn T, Santelmann K, Ma Z. Fluidized-bed Technology Enabling the Integration of High Temperature Solar Receiver CSP Systems with Steam and Advanced Power Cycles. Energy Procedia 2015;69:1404-11.

[69] Ordóñez F, Caliot C, Bataille F, Lauriat G. Optimization of the optical particle properties for a high temperature solar particle receiver. Sol Energy 2014;99:299-311. 